\title{
Models of T cell antigen receptor activation: the puzzle still remained
}

\author{
Sumit Deswal ${ }^{\mathrm{a}, \mathrm{b}}$ \\ ${ }^{a}$ Department of Molecular Immunology, Max Planck Institute of Immunobiology and Epigenetics and Faculty of Biology III, University of \\ Freiburg, Stübeweg 51, 79108 Freiburg, Germany \\ ${ }^{\mathrm{b}}$ Spemann Graduate School of Biology and Medicine (SGBM), University of Freiburg, Germany \\ Corresponding address: Max Planck Institute of Immunobiology and Epigenetics, Stübeweg 51, 79108 Freiburg, Germany. E-mail: \\ deswal@immunbio.mpg.de, Tel.: +49-761-5108-314, FAX: +49-761-5108-423
}

\begin{abstract}
$\mathrm{T}$ cell antigen receptor (TCR) is a protein-complex expressed on all $\mathrm{T}$ cells of the immune system and is responsible for the activation of $\mathrm{T}$ cells when infectious agent is presented by an antigen presenting cell (APC) in the form of peptides bound to the major histocompatibility complex (pMHC). Despite numerous studies it is not clear what biochemical changes upon binding of antigen ligand to the extracellular domains of TCR leads to activation of intracellular signaling (a process known as TCR triggering). This review summarizes possible biochemical mechanisms for TCR triggering and discusses their comparative limitations and advantages in explaining various experimental observations.
\end{abstract}

Keywords: $\mathrm{T}$ cell antigen receptor, activation, model

\section{Introduction}

T cell antigen receptor (TCR or TCR-CD3) is a protein complex expressed exclusively in $\mathrm{T}$ cells and is composed of the variable TCR $\alpha$ and $\beta$ chains and the constant $\operatorname{CD} 3 \gamma, \operatorname{CD} 3 \delta$, $\mathrm{CD} 3 \varepsilon$ and $\mathrm{CD} 3 \zeta$ chains (Figure 1). $\mathrm{CD} 3 \gamma$ and $\mathrm{CD} 3 \delta$ chain are glycoproteins each of which form a heterodimer with non-glycosylated $\mathrm{CD} 3 \varepsilon$ chain. Along with the $\mathrm{CD} 3 \xi-\xi$ homodimer, these chains associate with the
TCR $\alpha \beta$ heterodimer to generate the full TCRCD3 complex [1]. The TCR-CD3 is responsible for activation of a $\mathrm{T}$ cell upon antigen encounter which then help in the activation of $\mathrm{B}$ cells by releasing helper cytokines (helper T cells) or kill the target cell directly by the secretion of cytotoxic effector molecules such as granzymes, perforin and granulysin.

Antigenic ligand binding to the TCR leads to the phosphorylation of immunoreceptor 
tyrosine-based activation motifs (ITAMs) of the CD3 complex by the Src family protein tyrosine kinase Lck, resulting in the membrane targeting and activation of another kinase, ZAP-70. Once activated, ZAP-70 phosphorylates several substrates, including the transmembrane adaptor protein, linker for activation of $\mathrm{T}$ cells (LAT). Phospho-LAT serves as an important point of divergence for signals initiated from the TCR by recruiting several effector molecules to the plasma membrane thus initiating multiple pathways essential for full $\mathrm{T}$ cell activation [2].

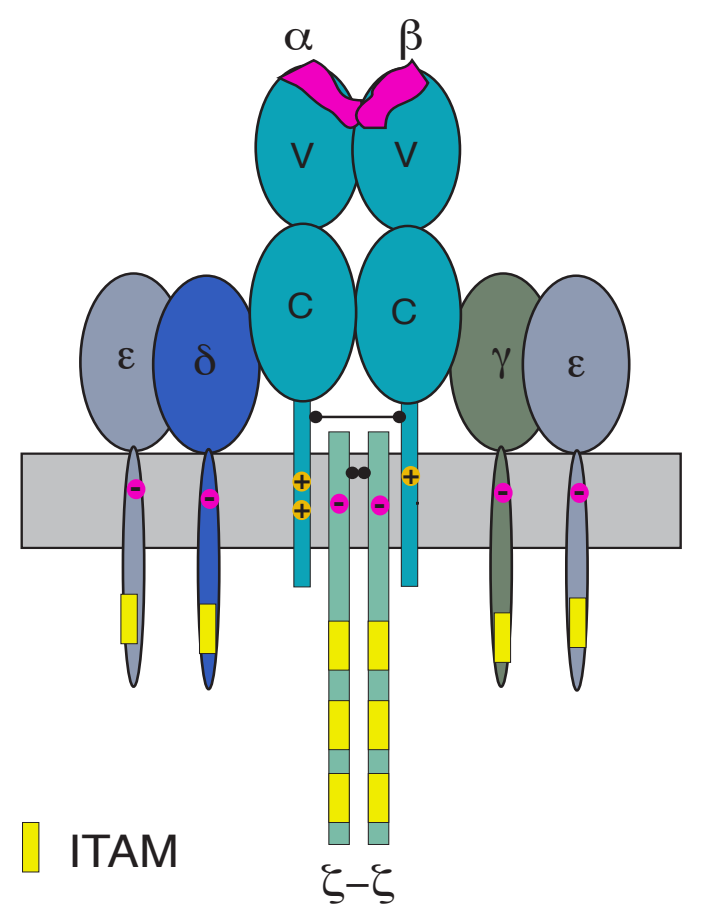

Fig.1: The TCR-CD3 complex. $V$ and $C$ represent variable and constant domains respectively for the TCR $\alpha$ and $\beta$. The hypervariable region that binds to the pMHC complex is shown in red color.
Although the downstream signaling mechanisms of $\mathrm{T}$ cell activation have been explored to quite detailed extent, the basic mechanism of how ligand binding to extracellular domains of $\operatorname{TCR} \alpha \beta$ leads to downstream signaling remained unclear. Several models of TCR triggering have been proposed based on the experimental findings, but none of the models so far could explain every aspect of TCR triggering. Broadly, these models can be grouped in three major processes which involve aggregation, conformational change or segregation (Figure 2). This review summarizes the proposed models of TCR triggering and discusses their comparative abilities for explaining various experimental observations (Table 1).

\section{Antigen induced clustering}

Several forms of clustering have been proposed as the triggering mechanism for the TCR. These include homodimer, heterodimer and the pseudodimer models as discussed below. 


\section{Clustering models}

a

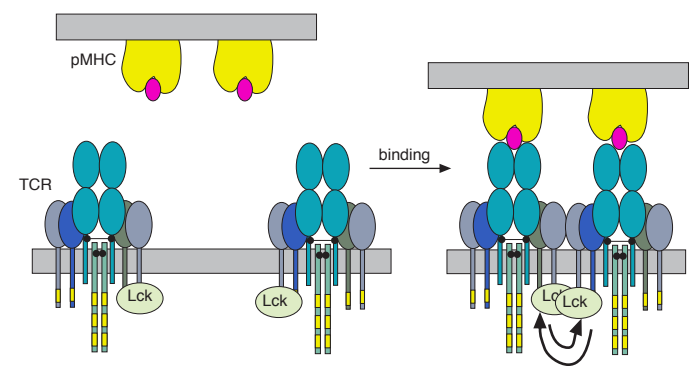

Conformational change models

d

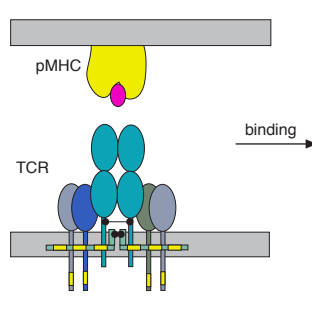

f

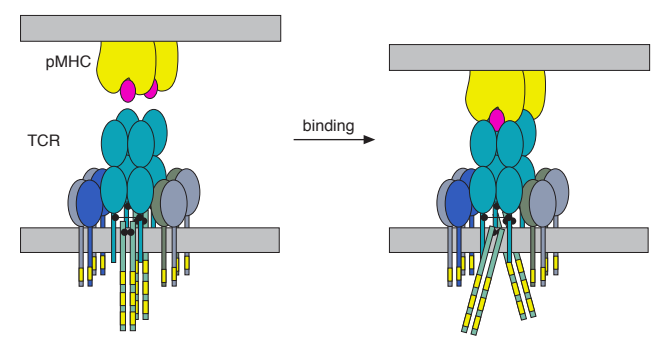

b

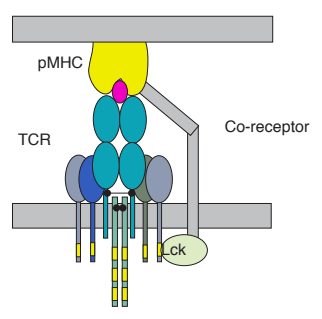

C

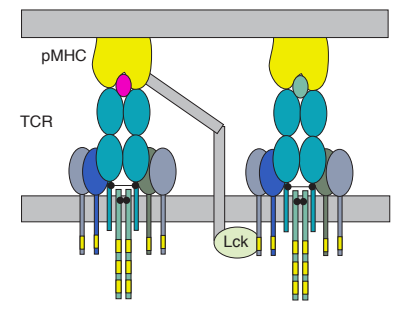

e

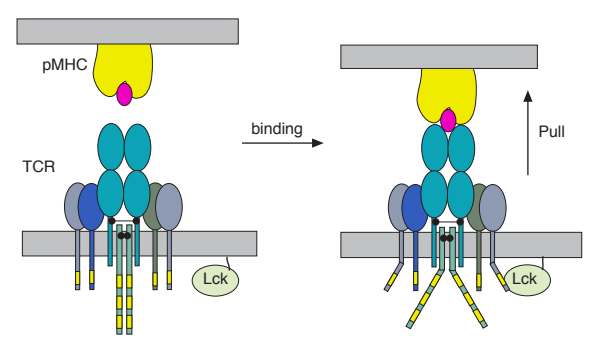

\section{Segregation models}

g

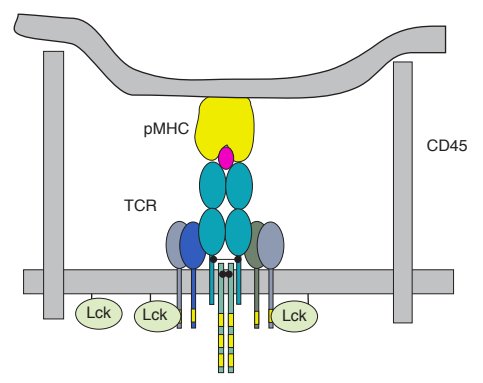

$\mathrm{h}$

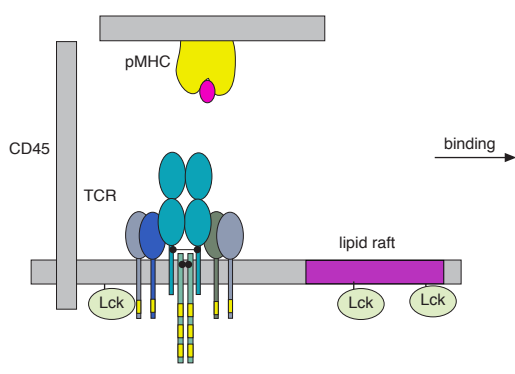

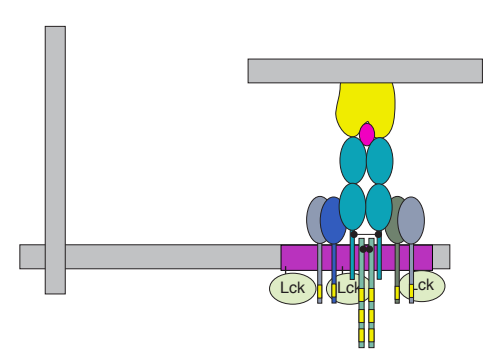

Fig.2: Various models of TCR triggering. a) Homodimer model, b) Heterodimer model, c) Pseudo-dimer model, d) Membrane binding model, e) Kinetic deformation model, f) Permissive geometry model, g) Kinetic segregation, h) Lipid raft mediated segregation model. Full description of each model is given in the main text. 
Table 1: Abilities of different models to explain various experimental observations.

\begin{tabular}{|c|c|c|c|c|c|c|c|c|}
\hline Observation & & & & Triggering & model & & & \\
\hline & Homodimer & Heterodimer & $\begin{array}{l}\text { Pseudo- } \\
\text { dimer }\end{array}$ & $\begin{array}{c}\text { Membrane } \\
\text { binding }\end{array}$ & $\begin{array}{c}\text { Kinetic } \\
\text { deformation }\end{array}$ & \begin{tabular}{|l} 
Permissive \\
geometry
\end{tabular} & $\begin{array}{c}\text { Kinetic } \\
\text { segregation }\end{array}$ & $\begin{array}{c}\text { Lipid } \\
\text { raft }\end{array}$ \\
\hline $\begin{array}{c}\text { Pre-clustered } \\
\text { TCR }\end{array}$ & No & Yes & Yes & Yes & Yes & Yes & Yes & Yes \\
\hline $\begin{array}{c}\text { Coreceptor } \\
\text { independent } \\
\text { triggering }\end{array}$ & Yes & No & No & Yes & Yes & Yes & Yes & Yes \\
\hline \begin{tabular}{|l|} 
Triggering by \\
soluble \\
nonomer pMHC
\end{tabular} & No & Yes & No & Yes & No & No & No & Yes \\
\hline $\begin{array}{l}\text { Triggering by } \\
\text { anti-CD3 } \\
\text { antibodies } \\
\end{array}$ & Yes & No & No & Yes & No & Yes & No & No \\
\hline $\begin{array}{l}\text { Activation by } \\
\text { pervanadate }\end{array}$ & No & No & No & No & No & No & Yes & Yes \\
\hline $\begin{array}{l}\text { Inhibition by } \\
\text { runcated CD45 }\end{array}$ & No & No & No & No & No & No & Yes & No \\
\hline \begin{tabular}{|l|} 
Inhibition by \\
longated pMHC \\
\end{tabular} & No & No & No & No & No & No & Yes & No \\
\hline \begin{tabular}{|c|} 
Triggering in \\
absence of self \\
pMHC \\
\end{tabular} & Yes & Yes & No & Yes & Yes & Yes & Yes & Yes \\
\hline
\end{tabular}

\section{a. Homodimer model}

Clustering of TCR-CD3 complexes following TCR engagement could lead to enhanced phosphorylation, for example by increasing the proximity of associated Lck molecules, resulting in the activation of the second receptor in the cluster by transautophosphorylation (or this enhanced proximity of kinases might lead to their transphosphorylation which enhance their activity to phosphorylate the receptor). This model is supported by the observations that artificial ligands such as pMHC tetramer and the antiTCR $\alpha \beta$ and anti-CD3 antibodies that crosslink the TCR lead to its activation whereas Fab fragment of these antibodies or the monomeric pMHC in solution fail to activate the TCR [3]. Also the observations that MHC class I $[4,5]$ and MHC class II [6] exist in pre-formed clusters, support the homodimer model. However, since several studies have now shown the existence of pre-clustered TCRs on the $\mathrm{T}$ cell surface $[7,8]$, it is difficult to imagine that clustering alone could trigger the 
TCR. In fact in a study by Schamel and colleagues [9], both clustering and conformational change were shown to be required for TCR triggering (permissive geometry model, as discussed later).

\section{b. Heterodimer model}

In the heterodimer model [10], coreceptor CD8 or CD4 binding to the same pMHC complex as the TCR brings the coreceptorassociated Lck kinase into proximity with TCR-CD3 ITAMs and their phosphorylation. Further it has been proposed that to fully activate the TCR, a pMHC ligand need to interact with a TCR-CD8 pair with a threshold time to induce stable zippering between the membrane-proximal domain of CD8 and the connecting peptide motif in the TCR $\alpha$ [11]. This allows stable association of Lck with the CD3 complex and results in complete phosphorylation of the CD3 ITAMs. A low-affinity pMHC ligand that interacts with a TCR-CD8 pair with less than threshold time induces incomplete zippering and therefore allows only transient Lck association and partial CD3 phosphorylation. However, the observations that $\mathrm{T}$ cells can develop and function normally in the mice lacking both CD4 and CD8 suggest that coreceptors are not absolutely required for TCR triggering and T cell activation $[12,13]$. Also the fact that anti-
CD3 antibodies and their $F\left(a b^{\prime}\right) 2$ fragments that do not engage the co-receptors can still activate the TCR $[14,15]$, indicates that coreceptors are not required for the TCR triggering itself, though they might be important for full activation of a $\mathrm{T}$ cell.

\section{c. Pseudo-dimer model}

Only a few MHCs carry high affinity agonist peptides for the TCRs, whereas a great majority of MHCs carry endogenous selfpeptides. On the basis of the crystallographic studies which showed that the CD4 tail associating with Lck was far from their own TCR/CD3 complex, the pseudodimer model postulates that two TCRs are brought together by binding low-affinity self or high-affinity agonist pMHC ligands and that the CD4 associated with a TCR engaging the agonist pMHC complex can assists in phosphorylation of neighboring TCR (engaged to low affinity self peptide) by the associated kinase Lck [16]. Thus according to this model, a 'pseudodimer' consists of one foreign and one self-antigen engaged receptor linked via CD4 molecule is the primary unit of TCR signal initiation module.

\section{Conformational change model}

Several studies have proposed conformational 
change as a requirement for TCR triggering $[17,18]$. However, how the ligand binding to TCR $\alpha \beta$ ectodomains leads to a conformational change in the cytoplasmic tails of CD3 subunits is not clear. The situation is complicated by the fact that the crystal structure of the fully assembled TCR-CD3 complex is not known, although individual subunits have been crystallized partially [1922]. Some of the important models for the mechanism of conformational change in TCRCD3 are discussed below.

\section{a. Membrane binding model}

According to this model, cytoplasmic tails

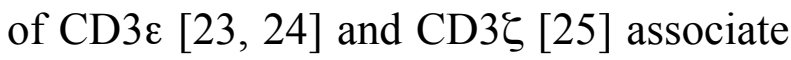
with the lipids present in the plasma membrane of a T cell. Thereby, the ITAMs are buried in the plasma membrane, making them inaccessible for phosphorylation by the kinases. Ligand binding leads to release of these CD3 chains from the plasma membrane, making them accessible to kinase and hence the phosphorylation.

\section{b. Kinetic deformation model}

Several line of evidence have proposed that the mechanical effects (such as pulling or shearing) of pMHC binding to the TCR leads to a piston-like displacement of the TCR-CD3 complex $[26,27]$. This induces a change in the conformation of the CD3 cytoplasmic domains, allowing ITAM phosphorylation.

\section{c. Permissive geometry model}

Based on the experimental evidence for the existence of TCR-CD3s in a pre-clustered form [7] and the fact that pMHC monomers in solution fail to trigger $\operatorname{TCR}[28,29]$ while pMHC dimer or higher oligomer can induce TCR triggering, the permissive geometry model was proposed[30]. According to this model, before ligand binding, the mono and multivalent TCR-CD3s exist in an autoinhibited state where ITAMs are inaccessible for phosphorylation by the kinase. Simultaneous dimeric (or higher order) ligand binding to the two TCR-CD3 complexes leads to a scissor-like movement in the two TCRCD3 complexes leading to exposure of their cytoplasmic tails, thus making the ITAMs accessible for phosphorylation.

\section{Segregation Model}

In a resting $\mathrm{T}$ cell, phosphorylation of the TCR-CD3 is kept in check by the active phosphotases. This is supported by the fact that pervanadate, a phosphatase inhibitor, 
treatment leads to strong phosphorylation of the TCR-CD3 ITAMs and also initiates the downstream signaling [31]. Thus any process that favors the kinase-phosphtase balance towards kinase, can lead to TCR-CD3 phosphorylation and the signaling. Redistribution of the TCR-CD3, kinases and phosphatases in which phosphatase is segregated from the TCR can interfere with the dephosphorylation. There are two mechanisms proposed for such ligand dependent re-distribution, which are discussed below.

\section{a. Kinetic segregation}

Kinetic segregation model was proposed based on the topological view of the cell surface molecules at the T cell-APC interface $[32,33]$. The tight intercellular contact causes the segregation of the molecules by sizes of their ectodomain resulting in physical separation of TCR from the large inhibitory tyrosine phosphatase CD45, leading to stable phosphorylation of TCR-CD3 ITAMs by Lck. Though sounding good in the context of a $\mathrm{T}$ cell - APC contact, the model fails to explain the activation of $\mathrm{T}$ cells by soluble antiTCR $\alpha \beta$ and anti-CD3 antibodies and the pMHC tetramer [14, 34].

\section{b. Lipid raft mediated segregation model}

Lipid rafts are the detergent (such as Triton X100, Brij-series, NP-40 or CHAPS)-resistant membrane microdomains which are enriched in glycosphingolipids, cholesterol and lipidmodified proteins such as the GPI-anchored proteins. Also these microdomains are enriched in double-acylated (myristoylated, palmitoylated) Src-family kinases and the important signaling molecules such as the coreceptors CD4 and CD8 and the adaptor protein LAT. Lipid raft mediated segregation model postulates that $\mathrm{pMHC}$ engagement results in partitioning of the TCR-CD3 complex into lipid rafts enriched in Lck and deficient in CD45 $[35,36]$. Partial support for this model comes from the observations that palmitoylation-deficient (and raft excluded) mutants of Lck and LAT are functionally defective. In addition, artificial targeting of other cytoplasmic molecules, such as SHP-1 [37], CD45 [38] or PLC $\gamma$ [39], to membrane rafts has marked functional effects on TCRinduced signaling. A connecting peptide in the TCR $\alpha$ chain and the $\operatorname{CD} 3 \delta$ chain were identified as the critical sites essential for effective raft association. Mutations in these components interfere with TCR signaling [40]. The mechanism of directing association of the engaged TCR complex with lipid rafts is not clear but might be based on co-engagement of the raft resident $\mathrm{CD} 4 / \mathrm{CD} 8$ coreceptors. 


\section{Conclusion}

Analysis of various proposed mechanisms reveals that probably a combination of these mechanisms is responsible for TCR triggering. Existence of pre-clustered TCR molecules rules out the homodimerization as a requirement for TCR triggering. It is possible that CD3 ITAMs are inaccessible for phosphorylation by the kinase in the resting state and some sort of conformational change is necessary for exposing the ITAMs, but additional studies are required to find out what mechanism is responsible for such conformational change. Segregation models argue the balance of kinase mediated phosphorylation and phosphatase mediated dephosphorylation shifts in favour of kinase upon ligand binding. Though such segregation might contribute for TCR triggering in the context of a $\mathrm{T}$ cell-antigen presenting cell interaction, it seems not the sole mechanism of TCR triggering as the soluble anti-TCR or anti-CD3 antibodies which do not induce segregation can still cause TCR triggering. Further studies on the structure of fully assembled TCR-CD3 complex will be required for a better understanding of the TCR triggering.

\section{References}

1. Call ME, Pyrdol J, Wiedmann M, Wucherpfennig $\mathrm{KW}$ : The organizing principle in the formation of the T cell receptor-CD3 complex. Cell 2002, 111:967-979.

2. Smith-Garvin JE, Koretzky GA, Jordan MS: T cell activation. Annu Rev Immunol 2009, 27:591619.

3. Cochran JR, Aivazian D, Cameron TO, Stern LJ: Receptor clustering and transmembrane signaling in T cells. Trends Biochem Sci 2001, 26(5):304-310.

4. Matko J, Bushkin Y, Wei T, Edidin M: Clustering of class I HLA molecules on the surfaces of activated and transformed human cells. J Immunol 1994, 152(7):3353-3360.

5. Fooksman DR, Gronvall GK, Tang Q, Edidin M: Clustering class I MHC modulates sensitivity of T cell recognition. Journal of immunology 2006, 176(11):6673-6680.

6. Unternaehrer JJ, Chow A, Pypaert M, Inaba K, Mellman I: The tetraspanin CD9 mediates lateral association of MHC class II molecules on the dendritic cell surface. Proceedings of the National Academy of Sciences of the United States of America 2007, 104(1):234-239.

7. Schamel WW, Arechaga I, Risueno RM, van Santen HM, Cabezas P, Risco C, Valpuesta JM, Alarcon $B$ : Coexistence of multivalent and monovalent TCRs explains high sensitivity and wide range of response. J Exp Med 2005, 202:493-503.

8. Lillemeier BF, Mortelmaier MA, Forstner MB, Huppa JB, Groves JT, Davis MM: TCR and Lat are expressed on separate protein islands on $\mathrm{T}$ cell membranes and concatenate during activation. Nat Immunol 2010, 11(1):90-96.

9. Minguet S, Swamy M, Alarcon B, Luescher IF, Schamel WW: Full activation of the $T$ cell receptor requires both clustering and 
conformational changes at CD3. Immunity 2007, 26(1):43-54.

10. Trautmann A, Randriamampita C: Initiation of TCR signalling revisited. Trends Immunol 2003, 24(8):425-428.

11. Palmer E, Naeher D: Affinity threshold for thymic selection through a T-cell receptor-coreceptor zipper. Nat Rev Immunol 2009, 9(3):207-213.

12. Locksley RM, Reiner SL, Hatam F, Littman DR, Killeen N: Helper T cells without CD4: control of leishmaniasis in CD4-deficient mice. Science 1993, 261(5127):1448-1451.

13. Schilham MW, Fung-Leung WP, Rahemtulla $A$, Kuendig T, Zhang L, Potter J, Miller RG, Hengartner $\mathrm{H}$, Mak TW: Alloreactive cytotoxic T cells can develop and function in mice lacking both CD4 and CD8. European journal of immunology 1993, 23(6):1299-1304.

14. Chang TW, Kung PC, Gingras SP, Goldstein G: Does OKT3 monoclonal antibody react with an antigen-recognition structure on human $T$ cells? Proc Natl Acad Sci U S A 1981, 78(3):18051808.

15. Kaye J, Janeway CA, Jr.: The Fab fragment of a directly activating monoclonal antibody that precipitates a disulfide-linked heterodimer from a helper $\mathrm{T}$ cell clone blocks activation by either allogeneic la or antigen and self-la. J Exp Med 1984, 159(5):1397-1412.

16. Krogsgaard M, Li QJ, Sumen C, Huppa JB, Huse $M$, Davis MM: Agonist/endogenous peptideMHC heterodimers drive $\mathbf{T}$ cell activation and sensitivity. Nature 2005, 434(7030):238-243.

17. Levin SE, Weiss A: Twisting tails exposed: the evidence for TCR conformational change. J Exp Med 2005, 201(4):489-492.

18. Gil D, Schamel WW, Montoya M, SanchezMadrid F, Alarcon B: Recruitment of Nck by CD3 epsilon reveals a ligand-induced conformational change essential for $T$ cell receptor signaling and synapse formation. Cell 2002, 109(7):901-912.

19. Sun ZY, Kim ST, Kim IC, Fahmy A, Reinherz EL, Wagner G: Solution structure of the CD3epsilondelta ectodomain and comparison with CD3epsilongamma as a basis for modeling $\mathbf{T}$ cell receptor topology and signaling. Proc Natl Acad Sci U S A 2004, 101(48):16867-16872.

20. Arnett KL, Harrison SC, Wiley DC: Crystal structure of a human CD3-epsilon/delta dimer in complex with a UCHT1 single-chain antibody fragment. Proc Natl Acad Sci U S A 2004, 101(46):16268-16273.

21. Sun ZYS, Seok Kim K, Wagner G, Reinherz EL: Mechanisms contributing to $T$ cell receptor signaling and assembly revealed by the solution structure of an ectodomain fragment of the CD3eg heterodimer. Cell 2001, 105:913923.

22. Kjer-Nielsen L, Dunstone MA, Kostenko L, Ely LK, Beddoe T, Mifsud NA, Purcell AW, Brooks AG, McCluskey J, Rossjohn J: Crystal structure of the human $\mathrm{T}$ cell receptor $\mathrm{CD} 3$ epsilon gamma heterodimer complexed to the therapeutic mAb OKT3. Proc Natl Acad Sci U S A 2004, 101(20):7675-7680.

23. Xu C, Gagnon E, Call ME, Schnell JR, Schwieters CD, Carman CV, Chou JJ, Wucherpfennig KW: Regulation of $\mathbf{T}$ cell receptor activation by dynamic membrane binding of the CD3epsilon cytoplasmic tyrosine-based motif. Cell 2008, 135(4):702-713.

24. Deford-Watts LM, Tassin TC, Becker AM, Medeiros JJ, Albanesi JP, Love PE, Wulfing C, van Oers NS: The cytoplasmic tail of the $T$ cell receptor CD3 epsilon subunit contains a phospholipid-binding motif that regulates $\mathbf{T}$ cell functions. J Immunol 2009, 183(2):10551064. 
25. Aivazian D, Stern LJ: Phosphorylation of $\mathbf{T}$ cell receptor zeta is regulated by a lipid dependent folding transition. Nat Struct Biol 2000, 7(11):1023-1026.

26. Ma Z, Sharp KA, Janmey PA, Finkel TH: Surfaceanchored monomeric agonist pMHCs alone trigger TCR with high sensitivity. PLOS Biol 2008, 6(2):e43.

27. Ma Z, Janmey PA, Finkel TH: The receptor deformation model of TCR triggering. Faseb $\mathrm{J}$ 2008, 22(4):1002-1008.

28. Stone JD, Stern LJ: CD8 T Cells, Like CD4 T Cells, Are Triggered by Multivalent Engagement of TCRs by MHC-Peptide Ligands but Not by Monovalent Engagement. I Immunol 2006, 176(3):1498-1505.

29. Cochran JR, Cameron TO, Stern LJ: The relationship of MHC-peptide binding and $T$ cell activation probed using chemically defined MHC class II oligomers. Immunity 2000, 12(3):241-250.

30. Minguet $S$, Schamel WWA: A permissive geometry model for TCR-CD3 activation. Trends Biochem Sci 2008, 33(2):51-57.

31. Secrist JP, Burns LA, Karnitz L, Koretzky GA, Abraham RT: Stimulatory effects of the protein tyrosine phosphatase inhibitor, pervanadate, on T-cell activation events. J Biol Chem 1993, 268(8):5886-5893.

32. Choudhuri K, Wiseman D, Brown MH, Gould K, van der Merwe PA: T-cell receptor triggering is critically dependent on the dimensions of its peptide-MHC ligand. Nature 2005, 436(7050):578-582.

33. Davis SJ, van der Merwe PA: The kineticsegregation model: TCR triggering and beyond. Nat Immunol 2006, 7(8):803-809.

34. Boniface JJ, Rabinowitz JD, Wulfing C, Hampl J, Reich Z, Altman JD, Kantor RM, Beeson C, McConnell HM, Davis MM: Initiation of signal transduction through the $T$ cell receptor requires the multivalent engagement of peptide/MHC ligands [corrected]. Immunity 1998, 9(4):459-466.

35. Horejsi V: Lipid rafts and their roles in T-cell activation. Microbes Infect 2005, 7(2):310-316.

36. Horejsi V: The roles of membrane microdomains (rafts) in $T$ cell activation. Immunol Rev 2003, 191:148-164.

37. Su MW, Yu CL, Burakoff SJ, Jin YJ: Targeting Src homology 2 domain-containing tyrosine phosphatase (SHP-1) into lipid rafts inhibits CD3-induced $\mathbf{T}$ cell activation. Journal of immunology 2001, 166(6):3975-3982.

38. He X, Woodford-Thomas TA, Johnson KG, Shah DD, Thomas ML: Targeting of CD45 protein tyrosine phosphatase activity to lipid microdomains on the T cell surface inhibits TCR signaling. European journal of immunology 2002, 32(9):2578-2587.

39. Veri $M C$, DeBell $K E$, Seminario $M C$, DiBaldassarre A, Reischl I, Rawat R, Graham L, Noviello C, Rellahan BL, Miscia $\mathrm{S}$ et al: Membrane raft-dependent regulation of phospholipase Cgamma-1 activation in $\mathbf{T}$ lymphocytes. Molecular and cellular biology 2001, 21(20):6939-6950.

40. Werlen G, Hausmann B, Palmer E: A motif in the alphabeta $\mathrm{T}$-cell receptor controls positive selection by modulating ERK activity. Nature 2000, 406:422-426. 